\title{
Discourse Patterns at Laboratory Practices and the Co-Construction of Knowledge by Applying SDIS-GSEQ
}

\author{
Edgardo Ruiz Carrillo ${ }^{1}$, José Luis Cruz González ${ }^{1}$, Samuel Meraz Martínez ${ }^{1} \&$ Luisa Bravo Sánchez ${ }^{1}$ \\ ${ }^{1}$ Facultad de Estudios Superiores Iztacala, Universidad Nacional Autónoma de México, México \\ Correspondence: Edgardo Ruiz Carrillo, Universidad Nacional Autónoma de México, Facultad de Estudios \\ Superiores Iztacala, Avenida de los Barrios No. 1, Los Reyes I1, México. E-mail: edgardo@unam.mx
}

Received: April 22, 2015 Accepted: June 5, 2015 Online Published: October 28, 2015

doi:10.5539/ies.v8n11p253 URL: http://dx.doi.org/10.5539/ies.v8n11p253

\begin{abstract}
The purpose of this study is to analyze the discourse through IRE (Intervention-Response-Evaluation) in the co-construction of knowledge of Biology students during laboratory practices by applying the SDIS-GSEQ software to assess IRE discourse patterns developed during the same. The study group consisted of second semester students of the Bachelor's Degree in Biology from the Facultad de Estudios Superiores Iztacala, UNAM. This process included audiovisual records of the practice, the creation of an instrument where a categories system and verbal sub-systems are put together with sub-categories to be defined based on the discourse and IRE structure; then this audiovisual records and the obtained category pattern were used to apply the SDIS-GSEQ software which was in charge of establishing the category sequences created in the interaction between teachers and students during the practice. The obtained results show IRE discourse patterns demonstrating that students prefer to use reproducible and dependent practice manual structures, instead of thoughtful and non-cognitive structures where their knowledge about the practice content is involved; the study also demonstrates that the SDIS-GSEQ software is a useful tool for the research of these patterns. Therefore, we propose to modify the IRE structure in order to create better conditions in the construction of knowledge between students and teachers by using a IRF (Initiation-Response-Feedback) pattern leading to feedback, negotiation and co-construction of knowledge so as to improve the Teaching-Learning process during laboratory practices.
\end{abstract}

Keywords: educational research, discourse analysis, student-teacher relationship, teaching and learning process, knowledge production

\section{Introduction}

Common speech properties have been highlighted in several discourse works. It is clear that in the classroom, speech has special properties that distinguish it from the one raised in other contexts. This means that the main element about it is that it encompasses interpretation rules that must be understood, negotiated and implemented by the participants beyond discourse structuring and the mere expression of such rules, which happens to be more implicit than explicit. In this regard, speech rules in the classroom are part of a broader set of unwritten interpretations, which are the basis for successful participation in the educational discourse.

Rigid discourse patterns with a structure of rules are common in traditional classrooms, where teachers and students speak according to very fixed views of their roles. The conversation in this case is very unilateral: the teacher asks all the questions and students have to answer them. Moreover, questions teachers ask are mainly closed questions, that is, questions that require students to demonstrate knowledge already acquired by the teacher. These questions usually require only short answers and do not generate structured language output by students.

This prevailing discourse pattern has been well documented (see Cazden, 2001; Stierer \& Maybin, 1994); however, literature shows that it is not the most appropriate pattern for learning opportunities as it leads to a turn-taking system in which the teacher assigns most intervention opportunities, which results in lower participation for students to select the topic of conversation by themselves (Mercer, 1995).

Cubero et al. (2008) presents a set of studies and research lines on the construction of knowledge and the role of educational discourse in these processes. Some of these lines are related to constructivist and sociocultural 
theories. He explains that socio-cultural settings define the shared co-construction of knowledge regarding various cultural domains, and it involves the creation of new forms of organization of semiotic mediation and action by all participants instead of accepting messages as these are communicated.

Exchange and negotiation processes on stage are performed through guided participation. For schools, this implies that the teacher is a guide for the students learning, while participating with them, offering various types of assistance. The educational goal would be that the students adapt these culture resources through their involvement with other expert individuals in joint activities (Cubero et al., 2007).

The work by Coll and Onrubia (2001) includes a series of strategies and discourse resources used by teachers and students in the performance of activities and the development of school contents. The role of language is explicit in all these strategies not only to represent and communicate meanings, but also as a tool to negotiate and develop systems of shared meanings, which should be progressively richer and more complex. The importance of joint activities performed by teachers and students to construct new meanings is extended to the whole learning process by raising the educational value of the discourse of participants in the classroom, which is also evident in the evaluation processes of the results of the learning experiences made by students, in this case, in the field of laboratory practices. An evaluation according to the authors cannot be separated from the evaluation of the teaching-learning process.

The use of questions is one of them, where teachers generally cause expected information since they are the "primary connoisseurs" in terms of pedagogical knowledge (Nassaji \& Wells, 2000). This discourse pattern, widely known as IRE and IRF (often called triadic dialogue), is designed for the teacher to start the discourse exchange (I), often in the form of a test or a visualization question, which predicts a student's response (R) providing known information. The choice for the teacher is then to evaluate (E) the response in terms of its proximity to the expectations or to provide feedback comments (F) (Mehan, 1979; Mercer, 1995).

Nunn (2001) argues that the classroom discourse sometimes depreciates the communicative teaching of the subject when both are confronted. This author agrees that due to the very repetitive structure of the discourse, the teacher faces a "ritual" representing the antithesis of the discussion in the classroom, but in his opinion, rituals are necessary and useful, and can serve as "framing devices 'embodying' a repertoire of options." Therefore, Nunn suggests to allow spontaneous improvisations based on interaction patterns, taking the IRF model (where F means 'tracking' or 'feedback,' since the function of this movement cannot be just evaluative) as a pattern. Based on data found in schools, Nunn suggests that the IRF structure is enriched by a new element called "negotiation" and marks it as N resulting in the elaboration of models such as INR, IRNRF, INNR, and so on. He claims that the rituals in teachers' classrooms do not exclude negotiated options and that they are a "potentially useful and flexible educational tool."

There is international evidence that suggests that the IRE style remains the dominant discourse, for example, in elementary classrooms in the United States, Russia, India, France and England (Alexander, 2000), and in the teaching of English in high schools of the US (Gutiérrez, 1994; Nystrand et al., 1997). Given the extensive knowledge base on these classroom processes and the availability of publications with ideas for altering the IRE as a dialogue pattern for IRF (Baddeley, 1992; Dawes et al., 2000; Morgan \& Saxton, 1991; Norman, 1992), this would cause teachers to have a repertoire of different strategies to develop their teaching practice.

These ideas aim to analyze, describe, and categorize the different discursive styles of the students in the practice, which on one hand intends to outline a theoretical framework that serves to unravel the relationships between the process of knowledge construction and the performance of the task. On the other hand, the purpose was to provide research results and solid experience based on research of classroom discourse in Coll and Edward (1996), Edward and Mercer (1994), Cros (2002), Ruiz et al. (2003a, 2003b) that serve to describe the precise mechanisms and strategies, in this case in achieving the goals of the practice.

The purpose of this research was to analyze discourse patterns through the IRE and IRF in the co-construction of knowledge (learning process) between Biology students in laboratory practices using the software SDIS-GSEQ. That is, to understand the way in which students achieve their goals in the practice through shared knowledge. This proposal arises from the different educational positions that have important implications for the interpretation and explanation of the construction of knowledge in the given context. This means paying special attention to descriptions and explanations made by students, that is, paying attention to their knowledge not only as a source of information, but also for personal reflection among themselves. Teaching and learning are essentially communicative since meanings are made there through a guided practice. According to this, it is necessary to promote the development of shared understandings and support the construction of appropriate discursive forms. 


\section{Method}

\subsection{Participants}

The study group consisted of 40 students ( 25 women, 15 men aged between 21 and 25 years old, middle class) from the second semester of Biology of the Facultad de Estudios Superiores Iztacala, from the Universidad Nacional Autónoma de México. The selection of participants was adjusted to the following admission criteria: a) being regular students of the Biology degree, b) being interested in participating in the study, and c) being a second semester student and to be studying the theoretical and practical module of Biomolecules.

\subsection{Justification of the Observational Methodology}

Every research process involves making many conceptual and methodological decisions, in which consistency plays a prominent role. The definition of a research problem or phenomenon and the choice of a scientific work strategy are two difficult moments of the process that scholars have to face when considering their proposal, and recognizing that there is a close relationship between the both of them becomes urgent. It is in this context that proposing a study of human communication, from an observational perspective, has its merits.

In this study, communication is taken as a multi-channel system in which only an outside observer, that is, a communication researcher can participate in it (Winkin, 1987). This idea highlights the importance of having a procedure that enables the collection, organization, and analysis of data, for the purpose of understanding this social phenomenon.

This observational study of interaction from the point of view of communication will follow the approach of the Systematic Observational Methodology (hereinafter known as MO) as defined by Anguera (1991, 1992, 1993), Bakeman and Gottman $(1986,1989)$, and its relevance to the human communication study (Anguera \& Izquierdo, 2006; Roustan, Izquierdo, \& Anguera, 2013). The MO is a strategy or a process whose main purpose is to expand knowledge in interest areas in the Social and Human Sciences. As a strategy, it proposes the study of the spontaneous behavior in natural contexts (Bakeman \& Gottman, 1986), and as a process, it is a specific access path to the quantification of behavior (Bakeman \& Gottman, 1989).

The MO, according to Anguera (1992, p. 23), agrees with the scientific research in general terms because it is a sequence of activities aimed to extend the scope of our knowledge. It is a systematic process aimed at the qualitative and quantitative study of the spontaneous behavior, from a data collection characterized by the development of appropriate coding systems as a means that enables its registry (Anguera, Magnusson, \& Jonsson, 2007). The $\mathrm{MO}$ is a rigorous process involving the delimitation of the research problem, the construction of instruments, and the application of analytical techniques. Systematic observation allows the study of communicative behavior in natural or prepared contexts in order to analyze the behavior under certain conditions referred to herein, with the purpose of having an audiovisual recording.

\subsection{Observation Instrument}

As a recording instrument, and in order to ensure maximum accuracy of data collection, two video cameras and two microphones were used and installed in the group's classroom. In accordance with the ethical standards approved by the American Psychological Association, the students of the group were aware that they were being filmed and they were indicated where the video cameras were located.

The observation instrument is a combination between a field format and a system of categories for each dimension considered. Field formats are characterized by the need of having a theoretical framework, and require the possibility of having a multiple and self-regulating coding (Anguera \& Izquierdo, 2006). Given the multidimensionality generated in a communicative episode, the construction of a proper observation instrument with the above mentioned characteristics is justified. Thus, the contents of the matrix generated seek to account for the enormous complexity of the information corresponding to the communication flow and it will be the turning point of the dichotomy between qualitative and quantitative perspectives.

Taking into account the passive observation of the video recordings and the objectives of the study, the axial criteria was established and the lists of behaviors and situations were developed until having a thorough and mutual exclusivity of the categories (E/ME): in order to carry out the systematic observation, ensuring the maximum quality of data, we define a system of categories for each one of the dimensions that are considered appropriate and relevant sources of data (in accordance with the research questions). Izquierdo (2001) argues that with the identification of the speaker, we then establish the who-to-who structure, the distribution of the speaker/listener roles, at every moment of the oral interaction. The interactive features of this activity are encoded by taking into account social functions that they meet (speech, relationship and task). Regardless of its length, each turn will be coded as a "whole" according to the dimensions considered, speaking and feedback. 
In this way, the coding generated based on the theoretical framework and the observations were included in Table 1:

Table 1. Categories of the discursive sequence, with code and definition

\begin{tabular}{|c|c|c|}
\hline Category & Code & Definition \\
\hline \multicolumn{3}{|l|}{ Ask } \\
\hline Confirming & Preconf & A question to clarify an assumption. \\
\hline Doubting & Predud & To make a question in order to find the knowledge that is not very clear. \\
\hline Orienting & Preori & A question oriented to the use or usefulness of any object. \\
\hline Ordering & Preord & A question to generate an action from the other. \\
\hline Affirming & Preafi & A question to confirm an assumption. \\
\hline $\begin{array}{l}\text { Based on the } \\
\text { text }\end{array}$ & Pretext & To ask a question based on an assumption included in the instruction manual. \\
\hline Evaluating & Preeva & $\begin{array}{l}\text { To ask in order to estimate knowledge or skills and performance according to the } \\
\text { purpose of a task. }\end{array}$ \\
\hline \multicolumn{3}{|r|}{1} \\
\hline Repeating & Rerep & To repeat what was said by the other. \\
\hline Guiding & Regui & A reply based on the procedure of a task. \\
\hline Doubting & Redud & A reply based on the knowledge that is not certain. \\
\hline Orienting & Reori & To reply with the elements of a task. \\
\hline Ordering & Reord & To reply and demand the fulfillment of a task. \\
\hline Confirming & Reconf & To reply by supporting the statement or explanation of the other. \\
\hline Reinterpreting & Rereint & To reply by re-constructing knowledge. \\
\hline Correcting & Recorr & To rectify what was said by the other. \\
\hline Explaining & Reexp & To reply by expanding the knowledge of the other. \\
\hline $\begin{array}{l}\text { Based on the } \\
\text { text }\end{array}$ & Retext & To answer a question based on the instructions manual. \\
\hline Denying & Reneg & To deny the statement or explanation of the other. \\
\hline Affirming & Reafi & To affirm a knowledge. \\
\hline \multicolumn{3}{|l|}{ Evaluate } \\
\hline Repeating & Evarep & Evaluate by confirming the knowledge of others. \\
\hline Participating & Evapar & Evaluate by accompanying the knowledge process of others. \\
\hline Correcting & Evacorr & Evaluate by rectifying the knowledge of others. \\
\hline \multicolumn{3}{|l|}{ Instruct } \\
\hline Correcting & Inscorr & Information to rectify the knowledge of others. \\
\hline Explaining & Insexp & To provide information to expand the knowledge of others. \\
\hline Clarifying & Insacl & To provide information to clarify the knowledge of others. \\
\hline Guiding & Insgui & To provide information to perform a task. \\
\hline Ordering & Insord & To provide information by demanding a task. \\
\hline
\end{tabular}

Regarding the database, the structural analysis was used, and the translation into language of SDIS (Sequential Data Interchange Standard) was performed in order to apply the program of sequential analysis GSEQ (Generalized Sequential Event Querier) (Bakeman \& Quera, 1996). The SDIS-GSEQ relies on an analytical technique developed by Bakeman (Bakeman, 1978; Bakeman \& Gottman, 1986) and by Sacket (1978, 1979, 1987), taking into account the premises in the works of Bakeman and Dabbs (1976) and the analysis of the sequential data allows to observe IRE and IRF patterns carried out during the practice.

\subsection{Analysis Techniques}

The identification of statistically significant patterns in the interactional communicative flow that takes place in conversations in the classroom was carried out by applying the techniques of sequential analysis of delays ( $\mathrm{Lag}$ ) and the detection of temporal patterns (T-Patterns); this is a combined analysis that can also be consulted in Anguera (2007), and Lapresa, Arana, Anguera, and Garzón (2013).

The origins of the sequential analysis of delays, as a procedure of sequential data analysis date back to studies by Gottman (1979), Sackett (1980, 1987), Bakeman (1978, 1991b), Bakeman, Adamson, and Strisik (1988), Bakeman and Quera $(1996,2001,2011)$ and Quera (1993). The ultimate objective of this type of analysis is the 
detection of behavior sequential patterns (Quera, 1993), which is carried out by means of the search of sequential contingencies between behavior categories or configurations, depending on the evaluation instrument used, whether it was the system of categories or the field formats, or a combination of both, as it is our case.

In the field of observational methodology, this technique is recognized as the most common form of microanalysis, because it consists essentially in finding out how the probabilities of occurrence of certain behaviors change based on the previous occurrence of others, that is, by comparing behavioral measures obtained diachronically.

According to Anguera (1983, p. 137), the technique of sequential analysis of delays:

"facilitates, if not the direct and exact identification of occurrence patterns between behaviors, an approximation of this, and it is an advantage compared to Markov methods, since: a) it allows to obtain contingency measures between distant behaviors in order (sequential events) or in time (length): b) it makes it possible to obtain direct measures of cyclicity for a single behavior (auto contingency) or phase relationships between several behaviors (cross contingency)."

On the other hand, the detection of temporal patterns allows the detection of statistically significant time patterns in behavior sequences, by implementing an algorithm that takes into account not only the order and sequence of events, but also the hierarchical organization of complex patterns. It is based on the assumption that "observers often perceive human behavior in interactions as something structured and repetitive, but they find it hard or impossible to specify what types of patterns are repeated and when" (Magnusson, 2000, p. 93); it highlights the importance of time in the organization of human behavior and it arises as a technique for the identification of the structure of a complex behavior system (Magnusson, 1996).

\section{Results}

The information obtained by the sequential analysis of delays allows to observe the probability levels $\mathrm{Z}$ and $\mathrm{P}$, with which the discourse flow can be interpreted in the interaction by selecting adjusted residuals and consider them as excitatory and by promoting the category $(\mathrm{Z}>1.96)$ and the inhibitory residuals which prevent categories in the sequence $(Z<-1.96)$. These levels were observed in Teacher-Student $(M-A)$, Teacher-Teacher $(M-M)$, and Student-Teacher (A-M) sequences at delays of 1 to 3, and these are explained below:

In the M-A sequential analysis (see Table 2 ) it can be seen that the Preeva category generates a constant inhibitory association with Predud $(\mathrm{Z}=-2.54, \mathrm{P}=0.05)$ and an excitatory association with $\operatorname{Reexp}(\mathrm{Z}=2.70, \mathrm{P}=0.01)$, while Inscorr generates an excitatory association with Redud $(Z=1.97, P=0.05)$ and Reneg $(Z=4.47, P=0.01)$, Insgui a predictive constant association with Predud $(Z=2.77, P=0.01)$, as well as Insacl with $\operatorname{Reconf}(Z=2.79$, $\mathrm{P}=0.01$ ); this shows that when a student asks a question doubting, this is inhibited by the evaluating question of the teacher, but it is encouraged when the teacher guides it. When the teacher instructs by correcting, he causes the student to respond by denying or doubting his own knowledge. When the teacher instructs through guiding, he causes the student to ask doubting. When he instructs by clarifying, the student responds by confirming the knowledge. 
Table 2. Values $\mathrm{Z}$ and $\mathrm{P}$ of the teacher-Student sequence in delay 1

\begin{tabular}{|c|c|c|c|c|c|c|}
\hline$Z$ value & Conditioned & & & & & \\
\hline Given & Predud & Preord & Redud & Reconf & Reexp & Reneg \\
\hline Preeva & -2.54 & -0.71 & 1.05 & 0.48 & 2.7 & 0.51 \\
\hline Inscorr & -0.8 & -0.16 & 1.97 & -1.07 & -0.4 & 4.47 \\
\hline Insacl & -1.77 & -0.35 & 0.17 & 2.79 & -0.88 & -0.5 \\
\hline Insgui & 2.77 & -0.6 & -0.93 & -1.48 & -0.55 & -0.55 \\
\hline Insord & 0.88 & 4 & -0.75 & 0.21 & -0.64 & -0.36 \\
\hline$P$ value & Conditioned & & & & & \\
\hline Given & Predud & Preord & Redud & Reconf & Reexp & Reneg \\
\hline Preeva & $\sim .01$ & $\sim .48$ & $\sim .29$ & $\sim .63$ & $\sim .01$ & $\sim .61$ \\
\hline Inscorr & $\sim .42$ & $\sim .88$ & $\sim .05$ & $\sim .29$ & $\sim .69$ & $\sim<.01$ \\
\hline Insacl & $\sim .08$ & $\sim .73$ & $\sim .86$ & $\sim .01$ & $\sim .38$ & $\sim .62$ \\
\hline Insgui & $\sim .01$ & $\sim .55$ & $\sim .35$ & $\sim .14$ & $\sim .58$ & $\sim .39$ \\
\hline Insord & $\sim .38$ & $\sim<.01$ & $\sim .45$ & $\sim .84$ & $\sim .52$ & $\sim .72$ \\
\hline
\end{tabular}

The sequential analysis for Delay 2 is performed ignoring the immediate previous data sequence, showing the relationship between the first and third data in the MA relationship (Table 3). Inscorr is associated with Preori in an excitatory way $(Z=4.16, P=0.01)$, as well as with Retext $(Z=3.53, P=0.01)$. Insacl generates a positive association with Reori $(\mathrm{Z}=3.57, \mathrm{P}=0.01)$. Insgui shows an association with Predud $(\mathrm{Z}=2.39, \mathrm{P}=0.02)$ and Insord with $\operatorname{Reconf}(Z=2.04, P=0.02)$. This can be interpreted since, after a first pattern of behavior, when the teacher instructs by correcting, it leads the student to question the use or usefulness of an object, or to give an answer based on the text or manual of the activity. When the teacher instructs by clarifying, the student responds based on the elements of the task. When the teacher instructs through guiding, the student asks while seeking knowledge he is not certain of, and when the teacher gives information while demanding a task, the student responds confirming the action shown in the first pattern.

Table 3. Values $\mathrm{Z}$ and $\mathrm{P}$ of the teacher-student sequence in delay 2

\begin{tabular}{|c|c|c|c|c|c|c|}
\hline $\mathrm{Z}$ value & Conditioned & & & & & \\
\hline Given & Predud & preori & preafi & Reori & reconf & Retext \\
\hline Preeva & -0.63 & -0.45 & 2.26 & -0.45 & -0.77 & -1.05 \\
\hline Inscorr & -0.55 & 4.16 & -0.24 & -0.24 & -1.26 & 3.53 \\
\hline Insacl & -0.99 & -0.29 & -0.29 & 3.57 & 1.84 & -0.66 \\
\hline Insgui & 2.39 & -0.77 & -0.77 & -0.77 & -1.59 & -1.8 \\
\hline Insord & -0.69 & -0.2 & -0.2 & -0.2 & 2.04 & -0.46 \\
\hline$P$ value & Conditioned & & & & & \\
\hline Given & Predud & preori & Preafi & Reori & reconf & Retext \\
\hline Preeva & $\sim .53$ & $\sim .65$ & $\sim .02$ & $\sim .65$ & $\sim .44$ & $\sim .29$ \\
\hline Inscorr & $\sim .40$ & $\sim<.01$ & $\sim .81$ & $\sim .81$ & $\sim .21$ & $\sim<.01$ \\
\hline Insacl & $\sim .32$ & $\sim .78$ & $\sim .78$ & $\sim<.01$ & $\sim .07$ & $\sim .51$ \\
\hline Insgui & $\sim .02$ & $\sim .44$ & $\sim .44$ & $\sim .44$ & $\sim .11$ & $\sim .07$ \\
\hline Insord & $\sim .49$ & $\sim .84$ & $\sim .84$ & $\sim .84$ & $\sim .04$ & $\sim .65$ \\
\hline
\end{tabular}

While analyzing Delay 3 (Table 4), associations between the first and fourth sequence data are generated. First, a 
positive association can be observed between Evarep and Reexp $(Z=2.77, P=0.01)$, Inscorr and Reord $(Z=5.00$, $\mathrm{P}=0.01)$ and between Insacl and Reori $(\mathrm{Z}=2.04, \mathrm{P}=0.04)$. This shows that when the teacher evaluates by confirming the knowledge of his students, after two behaviors, students answer by expanding their knowledge. When the teacher gives information to correct a student's knowledge, the latter responds by demanding another partner the fulfillment of a task, however, when the teacher instructs by explaining the knowledge, students respond based on the elements of a task.

Table 4. Values $\mathrm{Z}$ and $\mathrm{P}$ of the teacher-student sequence in delay 3

\begin{tabular}{lccc}
\hline$Z$ value & Conditioned & & \\
\hline Given & Reori & Reord & Reexp \\
\hline Evarep & -0.16 & -0.12 & 2.77 \\
\hline Inscorr & -0.29 & 5 & -0.64 \\
\hline Insacl & 2.04 & -0.32 & -1.01 \\
\hline P value & Conditioned & & \\
\hline Given & Reori & Reord & Reexp \\
\hline Evarep & $\sim .87$ & $\sim .91$ & $\sim .01$ \\
\hline Inscorr & $\sim .77$ & $\sim<.01$ & $\sim .52$ \\
\hline Insacl & $\sim .04$ & $\sim .75$ & $\sim .31$ \\
\hline
\end{tabular}

Table 5 shows the analysis of the teacher's discourse sequence to the students' silence, engaging in a dialogue intended to generate a possible participation thereof, in which inhibitory associations can be observed between Preeva and Preeva $(Z=-2.56, P=0.01)$ and excitatory associations with Insexp $(Z=3.24, P=0.01)$. Moreover, Evarep promotes the presence of Insgui $(Z=2.39, P=0.02)$, Insexp generates Preeva $(Z=3.34, P=0.01)$, and inhibits Insgui $(Z=-2.49, P=0.01)$, and Insgui induces Insord $(Z=1.97, P=0.05)$. This is interpreted as: when the teacher asks by evaluating and silence occurs, and then he continues instructing by explaining, which prevents him from asking again by evaluating. After this command, he asks again by evaluating, thereby preventing instruction by guiding, and when evaluating through repetition and silence is present, he proceeds to instruct by guiding, and if silence is repeated, he will teach by ordering.

Table 5. Values $\mathrm{Z}$ and $\mathrm{P}$ of the teacher-teacher sequence in delay 1

\begin{tabular}{lcccc}
\hline$Z$ value & Conditioned & & & \\
\hline Given & Preeva & Insexp & Insgui & Insord \\
\hline Preeva & -2.56 & 3.24 & -0.1 & -0.6 \\
\hline Evarep & -0.88 & -0.75 & 2.39 & -0.14 \\
\hline Insexp & 3.34 & -1.48 & -2.49 & -0.82 \\
\hline Insgui & -0.53 & -1.37 & 1.27 & 1.97 \\
\hline P value & Conditioned & & & \\
\hline Given & Preeva & Insexp & Insgui & Insord \\
\hline Preeva & $\sim .01$ & $\sim<.01$ & $\sim .92$ & $\sim .55$ \\
\hline Evarep & $\sim .38$ & $\sim .45$ & $\sim .02$ & $\sim .89$ \\
\hline Insexp & $\sim<.01$ & $\sim .14$ & $\sim .01$ & $\sim .41$ \\
\hline Insgui & $\sim .60$ & $\sim .17$ & $\sim .21$ & $\sim .05$ \\
\hline
\end{tabular}

When analyzing Delay 2 from M-M tables (Table 6), it can be observed that Preeva has a positive association with Preeva $(Z=3.19, P=0.01)$. Evapar induces the presence of Insexp in the sequence $(Z=2.24, P=0.02)$, Insexp 
inhibits Preeva $(\mathrm{Z}=-2.52, \mathrm{P}=0.01)$ and excites the presence of Insexp $(\mathrm{Z}=2.35, \mathrm{P}=0.02)$, and Insord $(\mathrm{Z}=2.31$, $\mathrm{P}=0.02)$, and Insgui induces Inscorr $(\mathrm{Z}=2.33, \mathrm{P}=0.02)$. This shows that there is a repetitive loop in asking through evaluation and teaching through explaining. In addition, the silence following a participatory evaluation leads the teacher to instruct through explaining, instructing through explaining decreases the presence of asking by evaluating in the sequence and motivates teaching by ordering if this continues, and when teaching through guiding after a student's action, the teacher instructs by correcting such action.

Table 6. Values $\mathrm{Z}$ and $\mathrm{P}$ of the teacher-teacher sequence in delay 2

\begin{tabular}{lcccc}
\hline$Z$ value & Conditioned & & & \\
\hline Given & Preeva & Inscorr & Insexp & Insord \\
\hline Preeva & 3.19 & -0.82 & -1.26 & -1.16 \\
\hline Evapar & -0.91 & -0.16 & 2.24 & -0.22 \\
\hline Insexp & -2.52 & -0.62 & 2.35 & 2.31 \\
\hline Insgui & 0.51 & 2.33 & -1.17 & -0.62 \\
\hline P value & Conditioned & & & \\
\hline Given & Preeva & Inscorr & Insexp & Insord \\
\hline Preeva & $<.01$ & $\sim .41$ & 0.21 & $\sim .24$ \\
\hline Evapar & $\sim .36$ & $\sim .87$ & $\sim .02$ & $\sim .82$ \\
\hline Insexp & $\sim .01$ & $\sim .53$ & $\sim .02$ & $\sim .02$ \\
\hline Insgui & $\sim .61$ & $\sim .02$ & $\sim .24$ & $\sim .54$ \\
\hline
\end{tabular}

Results in Delay 3 analysis (Table 7) do not show important data, except for a positive association of Inscorr with Inscorr $(\mathrm{Z}=4.36, \mathrm{P}=0.01)$, and Insacl with Inscorr $(\mathrm{Z}=2.29, \mathrm{P}=0.02)$ and Insord $(\mathrm{Z}=2.29, \mathrm{P}=0.02)$. This suggests two data after the teacher instructed by correcting, he does it again repeatedly, and when he instructs by clarifying, after two elements in the sequence, he instructs by correcting or ordering.

Table 7. Values $\mathrm{Z}$ and $\mathrm{P}$ of the teacher-teacher sequence in delay 3

\begin{tabular}{lcc}
\hline$Z$ value & Conditioned & \\
\hline Given & Inscorr & Insord \\
\hline Inscorr & 4.36 & -0.23 \\
\hline Insacl & 2.29 & 2.29 \\
\hline$Z$ value & Conditioned & \\
\hline Given & Inscorr & Insord \\
\hline Inscorr & $\sim<.01$ & $\sim .82$ \\
\hline Insacl & $\sim .02$ & $\sim .02$ \\
\hline
\end{tabular}

The A-M sequential analysis table (Table 8) shows the teacher's behavior induced by the student showing few significant results. In Delay 1, there is an excitatory association between Reconf and Evapar $(Z=2.01, P=0.04)$. In Delay 2, there are inhibitory associations between Redud and Preeva $(Z=-2.07, P=0.04)$ but positive between Redud and Inscorr $(\mathrm{Z}=2.78, \mathrm{P}=0.01)$, as well as with Insacl $(\mathrm{Z}=2.78, \mathrm{P}=0.01)$. In Delay 3 , there are positive associations between Reori and Inscorr $(Z=.77, P=0.01)$, and Reconf with both Insacl $(Z=2.15, P=0.03)$ and Insord $(\mathrm{Z}=1.97, \mathrm{P}=0.05)$. This shows that when the student answers by confirming, the teacher evaluates by paraphrasing. In Delay 2, when the student responds by doubting, he promotes the teacher to instruct by correcting or clarifying, but inhibits him asking through evaluating. In Delay 3, when the student responds by orienting, the teacher instructs by correcting. If the student answers by confirming, then the teacher instructs by clarifying or ordering. 
Table 8 . Values $Z$ and $P$ of the student-teacher sequence in delays 1 to 3

\begin{tabular}{|c|c|c|c|}
\hline$Z$ value & Conditioned & & \\
\hline Given & Evapar & & \\
\hline Reconf & 2.01 & & \\
\hline$P$ value & Conditioned & & \\
\hline Given & Evapar & & \\
\hline Reconf & $\sim .04$ & & \\
\hline \multicolumn{4}{|l|}{ Delay: 2} \\
\hline$Z$ value & Conditioned & & \\
\hline Given & Preeva & Inscorr & Insacl \\
\hline Redud & -2.07 & 2.78 & 2.78 \\
\hline$P$ value & Conditioned & & \\
\hline Given & Preeva & Inscorr & Insacl \\
\hline Redud & $\sim .04$ & $\sim .01$ & $\sim .01$ \\
\hline \multicolumn{4}{|l|}{ Delay: 3} \\
\hline$Z$ value & Conditioned & & \\
\hline Given & Inscorr & Insacl & Insord \\
\hline Reori & 3.77 & -0.55 & -0.38 \\
\hline Reconf & -0.73 & 2.15 & 1.97 \\
\hline$P$ value & Conditioned & & \\
\hline Given & Inscorr & Insacl & Insord \\
\hline Reori & $\sim<.01$ & $\sim .39$ & $\sim .70$ \\
\hline Reconf & $\sim .46$ & $\sim .03$ & $\sim .05$ \\
\hline
\end{tabular}

\section{Analysis of Results}

After analyzing the data provided by the SDIS-GSEQ software, it can be seen that when the teacher starts the IRE sequence with an evaluative question, this inhibits the presence of a question seeking a dubious knowledge, but increases the existence of responses broadening knowledge on the topic. In return, when it begins with a guided instruction, it predicts the existence of a dubious question by the student even in Delay 2. In addition, if teaching is performed by correcting, this results in either a response with dubious knowledge, or an answer canceling the knowledge of others, and in Delay 2, it causes a response based on the text or a question directed to the use or usefulness of an object.

The existence of the loop generated by the teacher to the student's silence (between an evaluative question and an instruction through explaining) shows the following: first, as the student remains silent, the teacher avoids repeating the evaluative question, and instead instructs by expanding knowledge aiming at bringing the student closer to the IRE sequence. Then, if the loop exists, it is because the student is not part of the sequence at that time, or rather, the teacher evaluates the silence as an answer and continues opening the sequence until the student can take part at one point, through responding by explaining.

When adding the data in which the student takes part in the interaction, several situations can be observed: firstly, when students answer with knowledge they are not certain of, the existence of an evaluative question in the chain is inhibited, and the existence of an instruction rectifying knowledge or making it explicit is increased. This in return creates a new loop between the teacher and the student: when the student answers doubting, the teacher instructs by correcting, and after that, the student can answer again doubting. Moreover, when generating this loop, the student has an opportunity to respond with various options and they can use outside elements whether to respond or to keep the conversation (an answer based on the text and asking about the use and usefulness of the instrumental equipment) without having to use or demonstrate knowledge acquisition.

This loop would persist if not because after the Redud-Insacl sequence, the student is able to respond supporting the other's statement or explanation, which leads the teacher to evaluate accompanying the learning process. 
This leads once again to the Insexp-Preeva loop, so that both loops are part of a discourse flow between the teacher and the student in search of common knowledge. But the situation where the dubious answer inhibits Preeva and generates the IRE Redud-Inscorr sequence shows that the student diverts the attention from the teacher if the chain starts in a situation where the student will have to end up responding with an explanation and will be unable to ask what he ignores. The student will prefer to stay on an IRE flow where the teacher has all the knowledge and the student is able to rely on external elements to be part of the co-construction.

The last sequence involves instructing by giving information to perform a task. This causes the student to be able to ask seeking knowledge, but if the student does not perform the result expected by the teacher, the former will end up demanding the task to be performed, which shows that within the IRE sequences, some of them intend to give orders instead of contributing to knowledge.

\section{Discussion}

After analyzing the results, a teacher-student/student-teacher interaction can be observed, where IRE plays a discourse structure role that leads to a hierarchy in the classroom based on knowledge, rather than a structure that leads to knowledge. As shown by Nassaji and Wells (2000), the student and the teacher keep a conversation in which the teacher is encouraged to transmit knowledge, therefore being the "primary connoisseur", and the student is kept in a passive position or where he can use the text to answer. This shows that IRE is a control structure rather than a knowledge negotiating structure and this practice situation is a sequence generated by both the teacher and the student, where the latter is more comfortable to be placed in a situation of not knowing and just being a recipient of the knowledge provided by the teacher.

This seems to show that it is not enough that the teacher asks evaluating and instructs through explanations during class to build knowledge. This situation eventually leads the student to respond by explaining, but when the situation is prevented, the loops created lead to a hierarchy rather than a negotiation of knowledge, thus making it necessary to use other discourse tools to alter the observed sequences.

Teachers and students adapt the use of language in accordance with the task in which they are involved. Although certain classroom activities can involve very little participation of students and a greater participation of IRE, other strategies (such as obtaining answers from students, discussions) may give rise to the participation of the student in a more active and complex way.

Given the evidence from observational studies that shows that when teachers ask to negotiate questions, students produce longer and more complex responses (Nassaji \& Wells, 2000), one of the issues for discourse sequences that promote collaboration would be to know the degree in which an adult prepares to consider the contribution of the student with the topic of the practice (Nassaji \&Wells, 2000).

A feasible tool involves the use of the discursive IRF pattern, since it allows to include more open communication elements, such as negotiation, where the student starts and induces new topics. Thus, the extended IRF pattern (explained in Baddeley, 1992; Dawes et al., 2000; Morgan \& Saxton, 1991; Norman, 1992) can be considered as a midpoint between the discursive routine and the opportunity for the student to include some variations. When the conversation structures applied to the IRF have succeeded, the teacher is no longer the one instructing, correcting, repeating and clarifying. Now the teacher is making movements that allow students to contribute and co-construct the understanding of a problem that has more than one answer correct and in which the objective is to reach a co-construction of knowledge after considering a variety of alternatives. This means that the teacher encourages the participation of students in their role of interpreting, starting, negotiating, affirming, clarifying and synthesizing knowledge built during the laboratory practice, which makes learning more effective.

As the focal point, if the intervention of the teacher is altered, not searching for an expected knowledge but searching for what the student ignores, it could help to generate new sequences that lead to a better negotiation and to the co-construction of knowledge. Therefore, it would be suggested that after an IRF sequence, the teacher changes its usual intervention to a reflexive intervention seeking to delve into what the student does not know or what prevents achieving the co-construction of knowledge in a more effective way.

Finally, the obtained results and the possibility of discourse pattern analysis, using the software SDIS-GSEQ as a tool to detect discursive structures in the classroom, show that it is a viable, effective and significant element to generate information leading to a research of discursive structures in the classroom in greater depth.

\section{References}

Alexander, R. J. (2000). Culture and pedagogy: International Comparisons in Primary Education. Oxford: Blackwell. http://dx.doi.org/10.2304/rcie.2006.1.3.301 
Anguera, M. T. (1983). Manual de prácticas de observación. México: Trillas

Anguera, M. T. (1992). Metodología de la observación en ciencias humanas. Madrid: Cátedra.

Anguera, M. T. (2007). Análisis de la temporalidad en registros observacionales de situaciones deportivas: ¿dos caras de una misma realidad? In A. Borges, \& P. Prieto (Eds.), Psicología y Ciencias Afines siglo XXI. Homenaje a Alfonso Sánchez-Bruna. Granada: Grupo Editorial.

Anguera, M. T. (Ed.). (1991). Metodología observacional en la investigación psicológica. Vol. 1. Fundamentación. Barcelona: PPU.

Anguera, M. T. (Ed.). (1993). Metodología observacional en la investigación psicológica. Vol. 2. Fundamentación. Barcelona: PPU

Anguera, M. T., \& Izquierdo, C. (2006). Methodological approaches in human communication. From complexity of situation to data analysis. In G. Riva, M. T. Anguera, H. Wiederhold, \& F. Mantovani (Eds.), From Communication to Presence: Cognition, Emotions and Culture towards the Ultimate Communicative. Amsterdam: IOS Press. http://dx.doi.org/10.1162/pres.16.5.559

Anguera, M. T., Magnusson, M., \& Jonsson. G. (2007). Instrumentos no estándar: Planteamiento, desarrollo y posibilidades. Avances en medición, 5, 63-82.

Baddeley, G. (1992). Learning Together through Talk: Multimedia Key Stage 1 and 2. London: Hodder and Stoughton.

Bakeman, R. (1978). Untangling streams of behavior: Sequential analysis of observation data. In G. P. Sackett (Ed.), Observing Behavior (Vol. 2): Data collection and analysis methods (pp. 63-78). Baltimore: University of Park Press.

Bakeman, R. (1991a). Prólogo. En M. T. Anguera (Ed.), Metodología observacional en la investigación psicológica (Vol. I., pp. 13-24). Barcelona: P.P.U.

Bakeman, R., \& Dabbs, J. M. (1976). Social interaction observed: Some approaches to the analysis of behavior streams. Personality and Social Psychology Bulletin, 2, 335-345. http://dx.doi.org/10.1177/014616727600200403

Bakeman, R., \& Gottman, J. M. (1986). Observación de la interacción: Introducción al análisis secuencial. Madrid: Morata.

Bakeman, R., \& Gottman, J. M. (1989). Observación de la interacción: Introducción al análisis secuencial. Madrid: Morata.

Bakeman, R., \& Quera, V. (1996). Análisis de la interacción: Análisis secuencial con SDIS y GSEQ. Madrid: Ra-Ma.

Bakeman, R., \& Quera, V. (2001). Using GSEQ with SPSS. Metodología de las Ciencias del Comportamiento, 3, 2, 195-214.

Bakeman, R., \& Quera, V. (2011). Sequential analysis and observational methods for the behavioral sciences. Cambridge: Cambridge University Press. http://dx.doi.org/10.1017/cbo9781139017343

Bakeman, R., Adamson, L. B., \& Strisik, P. (1988). Lags and logs: Statistic approaches to interaction. In M. H. Bornstein, \& J. Bruner (Eds.), Interaction in human development. Hillsdale, N.J.: Erlbaum.

Cazden, C. B. (2001). Classroom Discourse: The Language of Teaching and Learning (2nd ed.), Portsmouth: Heinemann. http://dx.doi.org/10.1017/s0047404500014676

Coll, C., \& Edward, D. (1996). Enseñanza aprendizaje y discurso en el aula. Madrid: Fundación Infancia Aprendizaje. http://dx.doi.org/10.1174/021037098320825253

Coll, C., \& Onrubia, J. (2001). Estrategias discursivas y recursos semióticos en la construcción de significados compartidos entre profesores y alumnos. Investigación en la escuela, 45, 7-19.

Cros, A. (2002). Elementos para el análisis del discurso de las clases. Cultura y Educación, 14(1), 81-97. http://dx.doi.org/10.1174/113564002317348138

Cubero, M., Cubero, R., Santamarina, A., Saveedra, J., \& Yossef, J. (2007). Aprendizaje y Psicología Histórico-Cultural. Aportaciones desde una Perspectiva Social del Aula. Investigación en la escuela, 62, 5-17.

Dawes, L., Mercer, N., \& Wegerif, R. (2000). Thinking Together: A programme of activities for developing 
thinking skills at KS2. Birmingham: Questions Publishing Company.

Edwards, D., \& Mercer, N. (1994). El conocimiento compartido. Barcelona: Ed. Paidós/MEC (Publicación original en inglés en 1988).

Gottman, J. (1979). Marital Interaction: Empirical investigations. New York: Academic.

Gutierrez, K. (1994). How talk, context, and script shape contexts for learning: A cross-case comparison of journal sharing. Linguistics and Education, 5, 335-365. http://dx.doi.org/10.1016/0898-5898(93)90005-u

Izquierdo, C., \& Anguera, M. T. (2001). The role of the morphokinetic notational system in the observation of movement.

Lapresa, D., Arana, J., Amguera, M. T., \& Garzón, B. (2013). Comparative analysis of sequentiality using SDIS-GSEQ and THEME: A concrete example in soccer. Journal of Sports Sciences, 31, 1687-1695. http://dx.doi.org/10.1080/02640414.2013.796061

Magnusson, M. S. (1996). Hidden real-time patterns in intra- and inter-individual Behavior. European Journal of Psychological Assessment, 12(2), 112-123. http://dx.doi.org/10.1027/1015-5759.12.2.112

Magnusson, M. S. (2000). Discovering hidden time patterns in Behavior. T-Pattern and their detection. Behavior Research Methods, Instruments \& Computers, 32(1), 93-110. http://dx.doi.org/10.3758/bf03200792

Mehan, H. (1979). Learning lessons. Cambridge, Ma: Harvard University Press. http://dx.doi.org/10.1017/s0047404500008708

Mercer, N. (1995). The Guided Construction of Knowledge. Clevedon, UK: Multilingual Matters.

Morgan, N., \& Saxton, J. (1991). Teaching, Questioning and Learning. London: Routlege

Nassaji, H., \& Wells, G. (2000). What's the use of 'triadic dialogue'?: An investigation of teacher-student interaction. Applied Linguistics, 21(3), 376-406. http://dx.doi.org/10.1093/applin/21.3.376

Norman, K. (1992). Thinking Voices. London: Hodder and Stoughton.

Nunn, R. (2001). Language learning across boundaries-Negotiating classroom rituals. Teaching English as a second foreign language, 5(2). Retrieved from http://www.tesl-ej.org/wordpress/issues/volume5/ej18/ ej18a1/?wscr=

Nystrand, M., Gamoran, A., Kachur, R., \& Pendergast, C. (1997). Opening dialogue: Understanding the dynamics of language and learning in the English classroom. New York: Teachers' College Press. http://dx.doi.org/10.2307/417942

Quera, V. (1993). Análisis secuencial. In M. T. Anguera (Ed.), Metodología observacional en la investigación psicológica (Vol. II). Barcelona: P.P.U.

Roustan, M., Izquierdo, C., \& Anguera, M. (2013). Sequential analysis of an interactive peer support group. Psicothema, 25(3), 396-401.

Ruiz, C. E. et al. (2003a). La práctica del profesorado universitario desde el análisis estratégico del discurso. Investigación en la Escuela, 49, 89-101.

Ruiz, C. E. et al. (2003b). Análisis teórico de la tolerancia como una percepción construida en el salón de clase. Educar, 32, 115-123.

Sackett, G. P. (1978). Observing Behavior (Vol. 2): Data collection and analysis methods. Baltimore: University of Park Press.

Sackett, G. P. (1979). The lag sequential analysis of contingency and cyclicity on behavioral interaction research. In J. D. Osofsky (Ed.), Handbook of infant development (pp. 623-649). New York: Wiley.

Sackett, G. P. (1980). An initial investigation of the usability of conversational data for doing Sociology. In D. Sudnow (Ed.), Studies in Social Interactions. New York: Free Press.

Sackett, G. P. (1987). Analysis of sequential social interaction data: Some issues, recent developments, and causal inference model. In J. Osofsky (Ed.), Handbook of infant development (pp. 855-878). New York: Wiley.

Stierer, B., \& Maybin, J. (1994). Language, Literacy and Learning in Educational Practice. Clevedon: Multilingual Matters. http://dx.doi.org/10.1017/s0272263100014042

Winkin, Y. (Ed.). (1987). La nueva comunicación (5th ed.). Barcelona: Kairós. 


\section{Copyrights}

Copyright for this article is retained by the author(s), with first publication rights granted to the journal.

This is an open-access article distributed under the terms and conditions of the Creative Commons Attribution license (http://creativecommons.org/licenses/by/3.0/). 